\title{
Cracking the Code of Press Headlines: From Difficulty to Opportunity for the Foreign Language Learner
}

\author{
MiCHAEL WHITE* \\ Universidad Complutense de Madrid
}

Received: 30 January 2010 / Accepted: 5 April 2010

\begin{abstract}
While press materials, are widely used both as an ESP materials resource and as a research source by ESP practitioners, press headlines in English confront the Non Native Speaker (NNS) and to some extent the Native Speaker (NS) with a notorious paradox: headlines are crafted to raise communication potential and yet, rather than communicate, they often perplex the reader. This may be devastating for motivation on the part of the English-as-a-foreign-language (EFL) student where even those at advanced level suffer frustration on failing to cope with headlines. The main arguments of this article are that headline perplexity is generated by the very communicatively driven strategies used in their configurations, that these strategies form patterns and that these patterns can be singled out and analysed in such a way as to enable the student to crack the code and thereby turn a liability into an asset, a stumbling block into a stepping stone.
\end{abstract}

\section{KEYWORDS:}

Headlines, headline spin, idiom variation, interface, double grounding, ESP.

\section{RESUMEN}

Los materiales de prensa constituyen un recurso muy atractivo para la clase de inglés como lengua extranjera y el primer contacto con dichos recursos es característicamente a través del titular. A pesar de que el titular esté diseñado para atraer y captar al lector, muy a menudo resulta de difícil comprensión incluso para el estudiante avanzado en lengua inglesa y esto puede hacer estragos en cuanto a motivación y confianza por parte del alumnado. El artículo actual se propone combatir esta paradoja mediante un análisis estructural de titulares. Mantiene que dichos titulares utilizan pautas sistemáticas que una vez expuestas y analizadas proporcionan al alumnado las claves para su comprensión. El objetivo es doble: por un lado facilita la comprensión y mejora la motivación por parte del alumno y, por otra parte, le ayuda a dominar mejor los entresijos de la sintaxis y la fraseología de la lengua inglesa.

\section{PALABRAS CLAVE:}

Titulares, pautas estructurales en titulares, idiomaticidad, interfaz, juegos de palabras, inglés para fines específicos.

\footnotetext{
*Address for correspondence: Michael White. Escuela Universitaria de Estudios Empresariales. Universidad Complutense de Madrid. Avenida de Filipinas 3, 28003, Madrid, Spain. Tel: 0034913946787 ; E-mail: white@filol.ucm.es
} 


\section{INTRODUCTION}

Headlines constitute a privileged genre in a number of senses. They are privileged by the initial position they occupy (Baicchi, 2003), the space they command, the bold print and size they are allotted and by the frequent syntactic and semantic unorthodoxy they entail vis-à-vis conventional sentence structure. This latter constitutes a salient difficulty factor for the ESP learner. Our analysis will show that, despite the apparent abnormality found in headlines, the end result is nevertheless a discourse that is decidedly idiomatic and it is this idiomaticity which perhaps poses the greatest difficulty for the second language learner. A finding made by Crawford Camiciottoli (2007: 65) is very relevant in this respect. She found that idiom usage by native and non-native speakers of English in giving business lectures in English showed a much lower frequency in the speech of the non-native lecturers. This is, I claim, indicative of the difficulty of mastering the code of a foreign language, the idiomaticity which is inherent to any language. Secondly, if headlines are a masterful use and manipulation of the code of a language, then explicit focus on headline patterns will provide a window to observe both how that manipulation occurs, how it exemplifies a heightened use of idiomaticity and eventually help the student to become more familiar with the phenomenon.

Bell (1991: 186) points out that the key to the actual writing of a successful press article is not a title but an effective lead -the title characteristically is not part of the agenda of the journalist writing the article but is the job of a specialist in that field, a sub-editor. The task of the lead is to summarise the ensuing article. Bell (1991: 150) adds: "The headline is an abstract of the abstract. The lead pares the story back to its essential point, and the headline abstracts the lead itself." Not surprisingly then, a lead is very often a complex sentence attempting to summarise what is most likely a multi-faceted complex issue. Now, if such a summary requires a complex sentence how does a headline manage to distil that lead drastically and yet be in itself an effective summary? While a headline may be a summary of the lead or at least the headline may draw on some specific part of that lead, it's length, a mere fraction of the length of the lead, means it can in no way rival the latter in so far as completion and must necessarily adopt another strategy.

Bell (1991: 189) singles out summarisation and attracting the reader as the essential headline functions. Dor (2003) who, like Bell, enjoyed the privileged position of practising journalism as well as being a linguist, gives a very comprehensive list of headline criteria ${ }^{1}$ which can be seen to largely hold with respect to headlines in general. At the same time, however, headlines may flout some of these criteria, even to the extent that counter criteria may be considered to form a pattern in themselves or qualify as a headline characteristic in their own right. In this respect, I have especially in mind the issue of ambiguity and its expressive potential (Ifantidou, 2009: 701; Brône \& Coulson, 2010: 220). While headlines in English may make extensive use of orthodox sentence structure, what poses greatest difficulty for the ESP learner are the unorthodox structures. Such unorthodox structures are brought 
about by characteristic headline use of phonic contrivances, morpho-syntactic density, a pronounced use of metaphor and metonymy, use and manipulation of fixed expressions, idioms and quotations as well as other complex manipulations. These factors will be examined in the light of real evidence from press sources, mainly from 2008 to the present day. Of specific interest will be the clarity/ambiguity tension, with the latter being shown as a sustained headline pattern, a source of difficulty even for the native-speaking reader and, of course, a pitfall for the foreign language learner. The logic of the pattern will be interpreted on a cost/benefit basis where the claim is that there is a communicative trade off to ambiguity and difficulty. Ostensibly, the trade off outweighs the extra effort posed by the difficulty (Brône \& Coulson, 2010: 228).

Metaphor in headlines will be examined for its own sake and also particularly from the point of view of creativity. In this respect, I also consider the creative use of idioms in headlines giving special consideration to idiom variation (Langlotz, 2007), something I claim bears a twofold difficulty for the ESP learner: in the first place, the difficulty involved in the idiom itself but secondly and specifically the difficulty of recognising the conventional idiom behind a varied form (Herrera \& White, 2010).

The pattern variously labelled interface (White \& Herrera, 2009) ${ }^{2}$, double grounding (Brône \& Feyaerts, 2005; Brône and Coulson, 2010) or topic-triggered metaphor (Koller, 2004; Semino, 2008) will be dealt with extensively. This is the characteristic headline pattern whereby metaphor motivation does not immediately derive from a well-known conceptual metaphor but is triggered by the subject matter being dealt with in the ensuing article. That is to say, if the subject matter is aviation, agriculture, tourism or what ever, lexis which is characteristic of the semantic field of these subjects will be deployed, not in a literal sense, but in a figurative one, thereby triggering another pattern of ambiguity which again will be interpreted as a net contributor of communicative potential. This will be shown to be a particularly productive headline resource.

Finally, it is claimed that the detailed analysis of these patterns should empower the ESP learner, providing him or her with effective tools to cope with press headlines, familiarizing him or her with idiomaticity and thus qualitatively advance his/her language skills.

\section{HEADLAND THEORY}

Bbibliography on headlines is now quite vast, but it has largely been quite stable in claiming what their main functions are. Thus, from the classic account of Galtung and Ruge (1965) through Bell (1991) right up to Dor (2002), the most outstanding characteristic is considered to be summarisation of content and that this has to be given with clarity. On the other hand, headlines should attract the reader to the news item and encourage him or her to read on. While holding on to the latter requirement, recent work however tends to call the former into 
question or at least raise elements that are, if not contradictory with such principles certainly raise quite different perspectives. Ifantidou (2009) shows how headlines dismally fail in summarisation, Brône and Coulson (2010) show that in contrast to clarity, deliberate ambiguity is often strategically sought in headline construction and White and Herrera (2009) have likewise been working along similar lines. Headlines must summarise the ensuing article but many headlines no more summarise that article than the Tower Bridge, the Statue of Liberty or a Spanish Bullfighter in bullfighting attire summarise Britain, the USA or Spain for the non-nationals of these countries respectively. However, what those images do is to provide a metonymic trigger which very effectively gives access to those concepts. Many headlines, I argue, operate in this way, though the trigger in these cases demands far more processing labour. This processing labour is due to the linguistic devices put into the crafting of the headlines. The criteria that a headline must attract the reader is indispensable and, here, my argument will be that those same linguistic devices play a major role in bringing about such attraction. On the other hand, an offshoot of such headline crafting is that it easily clashes with the clarity principle of headline writing. Furthermore, it is plain to be seen that if headlines pose extra processing costs for the native speaker (NS), this is all the more pronounced for the non-native speaker (NNS) or foreign language learner (FLL). Crafting ${ }^{3}$ operates by taking advantage of the phonic, syntactic or semantic resources of a language to produce a linguistic product which departs from a more conventional use of the language in question to a greater or lesser degree. I shall deal with these factors in the ensuing sections.

\section{PHONIC RESOURCES IN THE CRAFTING OF HEADLINES}

Many headlines show that ordinary sound enhancing devices such as alliteration, rhyme or rhythm are deliberately deployed in headline scripting. As ESP practitioners will know, alliteration as an enhancing device has played a major role in English literature diachronically. However, it may come as a surprise to them to find the device still crucial in contemporary English. On a basis of corpus evidence, Boers and Lindstromberg (2008) demonstrated the high incidence of alliteration and other phonic elements in the forging of idiomatic fixed expressions and they claim that where choices could have existed for an expression, combinations involving phonic patterning take precedence over those not entailing them. Thus, the fixed expression happens to be It takes two to tango and not It takes two to waltz, for example. In the case of headlines, the tendency to exploit this same device will mean that words will be chosen for the sake of generating a phonic pattern. This may mean added difficulty for the FLL: in the first place the lure of alliteration or rhyme, very noticeable for the NS and therefore an added extra to the headline, may pass the NNS unnoticed and, secondly, as words are chosen on phonic grounds, they may be rather marginal to the NNS's core word stock. Let us see some examples. 
1)

a) $\underline{\text { California currency chaos (Financial Times }=\text { FT 8/7/2009) }}{ }^{4}$

b) Cashless California (FT 29/5/09)

In these two cases as California is the given element, we see that the accompanying words are chosen to alliterate with it.

2) Detroit in distress (FT 2009)

This repeated section title to capture the plight of the automobile industry due to the crisis again follows the same alliterative principle. In all probability, if the city in question were Chicago or Ohio, the choice for the slot filled by distress would probably be different.

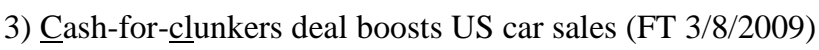

The official US car-scrappage plan (akin to the Spanish plan renove) was also crafted as Car Allowance Rebate System (CARS) but, despite the ingenuity engineering this acronym, it was quickly colloquialised into the alliterating slogan cash-for-clunkers where the latter word has additionally an onomatopoeic connection with the noisy sound of an old engine laboring to turn over. Needless to say, these characteristics pave the way for a rapid and easy entry of the term into headlines while the marginal nature of clunker can pose added difficulty for the NNS.

4) $\underline{\text { Cowen }}$ calls for calm (Irish Times 12/11/2010)

5) Cross your legs: Ryanair to implement fee per wee (Irish Times, 16/1/2010)

The comment by Ryanair's chief executive officer of charging passengers for in-flight toilet use is clearly worded to exploit colloquial words which additionally rhyme.

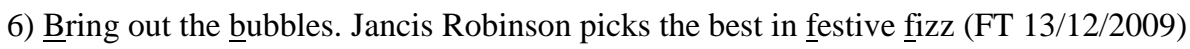

This example follows the same alliterative principle but, additionally, it makes use of colloquial metonymic terms for champagne, namely bubble and fizz. As well as the alliterative effect, the communicative effect of bonding with the reader through the ostensibly shared colloquial words may easily be lost on the NNS.

7) Markets poised to punish Spain (FT 28/2/2010)

Very probably the choice of poise in this headline owes a great deal to the alliteration and vowel contrast it establishes with punish.

(C) Servicio de Publicaciones. Universidad de Murcia. All rights reserved. IJES, vol. 11 (1), 2011, pp. 95-116 
8) $\underline{\text { Stocks }}$ stutter as dollar fades (FT 8/12/2009)

The rather unusual choice of stutter in this case could hardly but perplex a NNS and is clearly motivated merely for alliterative effect.

This alliterative tendency occasionally reaches paroxysm as in the following where again the choice of wording is very noticeably alliteratively driven:

9) Drugs, destructiveness, debts, disaster (Irish Times, 23/1/2010)

(Context: article on a Biography of Thomas de Quincey)

A more radical version of phonic deployment occurs in cases which involve the use of an alliterative, rhyming or otherwise stylistically balanced phrase which additionally involves a transformation or manipulation of a well-known existing expression or quotation which the NS immediately realises to underlie the headline phrase:

10) Taboo or not taboo. Some new office guidelines (FT 11/10/2009)

This headline, questioning political correction at the office, clearly gathers a lot of its momentum from the underlying Shakespearian dictum to be or not to be.

11) Dubai to all that. Why the party is over for the Emirates expats (FT 16/1/2009)

The likely NS reader of the Financial Times is highly likely to recognise the phonic proximity with Good-bye to all that, the title of Robert Graves' autobiographical work and additionally to bring to the headline some knowledge of the sentiments of disillusionment expressed in that work. Hence the headline capturing all those added factors equally manages to capture the reader's attention, something which is more than likely to pass the NNS by.

12) Dire Land. Irish republic faces prolonged recession (FT 30/8/2009)

The play here is with the phonic proximity of dire land and Ireland.

Likewise, a similar playful practice is employed in the following instantiations which operate replacing ears, great and push by pairs with minimal phonemic differentials, namely, fears, grape and Porshe:

13) a) Music to our fears (FT 6/2/09)

b) Grape expectations for a warm Ireland (Irish Times 30/12/09)

c) When Porshe comes to shove (FT 7/1/09) 
On the other hand, an actual expression may be used intact but at the same time have additional contextual phonic associations or implications:

14) Swiss throw a spanner in the works (Irish Times 16/1/2010)

The shock result in the opening world cup match of Spain 0 Switzerland 1 is captured by the above fixed expression but in all probability, the choice of this expression over others rested on the sound approximation between spanner and Spaniard.

The tendency to contrive, transform or manipulate, in the above examples engineered through phonic proximity, is crucial in headlines and will crop up again later on more semantic patterns.

\section{MORPHO-SYNTACTIC AMBIGUITY}

The pressure to squeeze a lot of content into a highly restricted space may often give rise to headlines that are extremely difficult to parse. This goes for NS so, obviously, difficulty for the NNS is increased and multiplied. This fact alone provides sufficient reason to quarantine the supposed headline requirement of clarity and avoidance of ambiguity. The parsing difficulty in this type of headline derives from such factors as word class ambiguity, extremely dense extended noun phrases, apparent ambiguity as to which word performs as verb (more than one candidate may suggest itself for a verbal role as the items of the phrase sequence are successively read or -the still more difficult case- even a rather lengthy headline phrase may completely lack a verb. On the other hand, what strategy can the ESP learner adopt so as not to throw in the towel where such complexity, indeed perplexity, is involved? Let us see the following cases.

15) EU draft rules for hedge funds attacked (FT 20/4/2009)

As we read EU draft rules, we could easily be inclined to classify draft as a verb and this classification can continue up to and including funds. Finally, if that had been our reading, when we eventually reach attacked, we are forced to backtrack and reclassify the chunk EU draft rules as a single noun phrase. The difficulty involved here for the ESP learner can be turned into an advantage as source for coming to terms with English noun phrase structure, and especially where extended noun phrases (ENPs) are involved as is particularly the case of the following example:

16) Ash cloud travel chaos hits airline shares (16/4/2009) 
Parsing again is quite problematic in this example until we hit hits and classify it as the verb. In the sequence ash cloud travel chaos, all four component elements could be expected to have characteristic noun functions (plus verb functions in the case of cloud and travel). Here the first three are recycled to an adjectival role and the ensuing ENP can be tapped in the ESP class as a source for demonstrating this typical convertibility in the case of English from one word class to another, something which can so easily perplex the FLL.

17) Cowen fury at BBC when not whether bailout claim (Irish Independent 14/11/2010)

Sheer ambiguity undoubtedly permeates this example. That ambiguity rests on numerous factors. Parsing can only advance with extreme difficulty. First, the headline is of considerable length and, nevertheless, lacks a verb. Secondly, the very beginning Cowen fury is a very unlikely collocate as it combines a proper name with a noun and leaves us wondering how to proceed. We know that omission or ellipsis is a common headline practice, so one option is to begin reinstating what we suspect may have been omitted. Syntactically feasible could be a possessive option or a verb option, for instance, Cowens fury or Cowen shows fury. Either of these would allow the string to proceed to at $B B C$, giving an acceptable syntactic combination up to that point, but how to proceed from there is still more perplexing as we must attach $B B C$ to the remaining fragment. Baicchi (2002) pointed out that headlines and titles are dependent on cataphoric reference for their interpretation. This is because their textual position means they lack anaphoric reference and this factor is a major contributor to difficulty of understanding. Such difficulty is even more pronounced in the case where headlines incorporate quotation fragments which desperately require anaphoric reference to the whole context to get a handle on meaning. That context may be re-enacted in the ensuing text so therefore, in keeping with Baicchi's point, cataphoric work must first be done before we backtrack anaphorically with our discovery to disentangle the headline. We have to wait until the second paragraph to find the relevant information -'The BBC report made the unsubstantiated statement that recourse to the EU bailout fund was no longer a matter of whether but when'. At this stage, therefore, we grasp an important fragment meaning, when not whether, which semantically sets up a scenario where the hypothetical factor of a future event (the whether) is categorically eliminated and therefore the prediction is that such an event is sure to take place with the only contingency or variable being the time factor of when (the when) it takes place.

This knowledge is indeed helpful but we are still left with a perplexing word string fragment, namely 'BBC when not whether' bailout claim'. Again the parsing issue arises. Given the penchant shown by headlines in English, it is feasible for a FLL groping towards meaning to consider the whole fragment to be an extended noun phrase. This hypothesis would be right but here the word class convertibility is even more complex than in the previous example. Establishing the head of the phrase to be claim, we are then left to discover 
what kind of claim by unravelling the modifiers. While $B B C$ and bailout do demand some elucidation, both being nouns converted to adjectival functions, the mind boggling element, especially for the FLL, must be when not whether. Before going into the semantic content, to convince students that this is a mere modifier, it might be a good strategy to do a substitution exercise highlighting the structure involved, replacing it by a simple one-word adjective, for instance, BBC new bailout claim -a possessive could also be added: 'BBC's new bailout claim'. When the meaning is explained, the whole headline can once more be used to elucidate how semantic density is achieved in headline discourse by piling up information in extended noun phrases and by taking advantage of prepositions to establish relation.

On the principles of salience (Giora, 2003; 2008), readers meet words in context (Durán \& Roldán, 2008) with per se established expectations and these can also be motivated by a lexico-grammatical framework as shown in the work of Hoey (2005). For instance, if we consider the following example:

18) Key mistakes leave children locked in cars (Irish Independent -paper edition21/9/2010)

Key, as characteristically a device for locking and unlocking (or perhaps, winding) and also in its figurative meaning as something vital or crucial are both conventional word meanings of high daily utility. However, saliency or expectation is clearly lexicogrammatically conditioned giving us a framework in which both meanings are clearly differentiated: key as noun-phrase head preceded by a qualifying adjective characteristically refers to the locking/unlocking (or winding) device, using a particular kind of key, whereas key in an adjectival position with an ensuing noun-phrase head characteristically refers to the figurative sense of key, meaning that the noun-head is vital or crucial in some way. Thus we get the pattern:

$\begin{array}{ll}\text { key as locking-unlocking (or winding) device } & \text { key meaning vital or crucial } \\ \text { car key } & \text { key vocabulary } \\ \text { door key } & \text { key figure } \\ \text { locker key } & \text { key decision } \\ \text { clock key } & \text { key move }\end{array}$

Hence as we read the phrase our lexico-grammatical hard wiring disposes us to initially construe the meaning as mistakes that are vital or crucial in some way. However, as we read the whole headline and especially the lead, we are obliged to reinterpret key mistakes, not as vital mistakes, but as mistakes made with keys. The point is once again that the headline writer has deliberately worded the sentence to exploit the communicative effect of a counter salient or unexpected meaning of key for the type of lexico-grammatical framing in which it arises. In 
other words, the headline writer is making it evident to the reader that he is so skilful with the rules of the language that he or she can subvert them and not only get away with it but reap added communicative effect by counter-salience effect. On the other hand, for the ESP student to pay attention to play of this type may allow him or her to master the convention of the language all the better.

\section{INTERFACE, DOUBLE GROUNDING OR TOPIC DRIVEN METAPHOR IN HEADLINES}

A highly productive strategy which provides headlines with greater metaphorical scope and simultaneously with a witty or humorous effect is that variously labelled interface (White, Herrera \& Amengual, 2004; White \& Herrera, 2009), double-grounding (Brône \& Feyaerts, 2005; Brône \& Coulson, 2010) or topic-triggered metaphor (Koller, 2004; Semino, 2008). This is a process whereby lexis from the semantic field of the topic or subject matter that is being dealt with provides the linguistic metaphor for an expression. Motivation in this case is therefore internal to the subject under discussion. For instance, if the subject matter is aviation, lexis from the semantic field of aviation, and which therefore would be normal for a literal role in this field, will be sought out to function figuratively. Metaphor motivation in cases like this, therefore, is not deriving from a different source domain but is internal to the topic or subject matter which is the object of treatment. Additionally, as Brône and Feyaerts (2005) and Brône and Coulson (2010) point out, metonymy plays a crucial role in the cognitive power of the strategy. The deliberate deployment of such a strategy and the artifice involved cannot but capture the attention of the reader or hearer in question and, given its characteristic use in that genre, this seems to be the goal in the case of headline writers. The following examples all deploy lexis which have a technical, core or literal meaning within the field of aviation but which are here not used in that core sense of flight but figuratively to refer to airline companies as business concerns:
a) Alitalia takes off amid protests (FT 13/1/2009)
b) Safety issues create headwinds for Airbus and Rolls-Royce (FT4/11/2010)
c) Air alliance runs into turbulence (FT 26/9/2009)
d) Dublin grounds Ryanair bid for Aer Lingus (22/1/2009)
e) Airbus flies into dogfight over military adventure (FT 10/2/2009)
f) British Airways and Iberia prepare for landing (12/11/2009)
g) Aeroflot investor put in tailspin by Kremlin plan (FT 28/12/2008)

The target concepts involved here are very characteristic of processes in general and, of course, of events in the business world in particular, namely, initiating a process (takes off), meet difficulties during a process (headwinds, turbulence), forbid (grounds), engage in 
outright conflict (dogfight), (here all the more cohesive and coherent since an established meaning of dogfight is a close-quarter aerial fight out between enemy planes and in this case, the subject matter is the military arm of rival aircraft manufacturers), approach a desired goal (prepare for landing), face impending disaster (tailspin) could each have been expressed in numerous ways but the headline writers have chosen a very specific strategy for a specific reason: because all the companies have to do with aviation, the deployment of core lexis from the semantic field of aviation is deliberately deployed figuratively for communicative purposes. This same process is observable in any field. For instance, the following examples dealing with car-company business or policy all use standard lexis from the semantic field of cars as mechanical objects for figurative purposes:

a) Ignition problems (FT 24/9/2009) (referring to slump in car sales)

b) When Ford got stuck in first gear (FT 13/2/2010) - referring to a failed rubber production enterprise by Ford).

c) General Motors go to the garage (FT 3/6/2009) - highlighting the company's need to remedy its own financial affairs.

d) F1 teams brake hard on costs (FT 5/9/2009) - referring to the sharp curtailment of F1 team budgets.

e) Magna in pole position for Opel decision (FT 20/8/2009) - highlighting that the company Magna is in a more advantageous position than other rival bidders to acquire Opel.

f) A shift in gear (FT 18/9/2009) -referring to the possible sale of Opel as making a significant change in the industry.

Again the concepts involved here all have to do with the nature of processes: getting a process going (ignition and stuck in first gear), remedying or pre-empting malfunction to enable the process to move forward more effectively (go to the garage), severely curtail or cut back a process (brake hard), to be in the most advantageous situation to take advantage of circumstances (pole position), a qualitative change in a process (shift in gear). The point is that as the subject matter has to do with the car industry, the motivation for the metaphoric expressions derives from within the core lexis of the semantic field of cars as mechanical vehicles or from their performance as such vehicles.

The strategy is equally deployed with respect to any conceivable subject matter as seen below.

Clothing:

21) Inditex chief tailors its strategy (FT 25/3/09) 
Music:

22) Hanks concedes Emi buy was off key (FT 17/9/09)

Volcanic eruption:

23) Ash casts a cloud over travel plans (Irish Times 5/5/2010)

Rail Transport:

24) Trains resume but public trust derailed (FT 21/12/09)

Food and Drink:

25) Coke keeps its fizz in face of downturn (FT 12/2/2009)

26) Austerity takes a slice out of ham sales (FT 28/12/2009)

27) Ferrero will not offer Cadburys a sweeter deal (FT 25/1/2010)

In all cases, we have a core word which would normally operate literally in the semantic field of these companies. We easily capture both the semantic import as we also notice the artifice, concluding that keep its fizz means that Coke is performing strong despite the crisis while a slice out of indicates that ham sales are suffering from that same crisis. In 27), the key issue being that as the core business of the respective companies is sweets and chocolates, this is what motivates the figurative presence of sweeter in the headline, meaning Ferrero will not offer Cadburys a better deal than rival Kraft has offered for the takeover of the British company.

Sports:

28) Cricket fanatic suddenly on a sticky wicket. (FT 12/2/2009)

Animals:

The fact that it is a dog that is trained to detect hospital superbugs motivates the choice of the verb sniff in the following example:

29) Sniffing out killer bugs (Irish Times 9/11/2010)

Energy:

30) Chinese businesses fuel cleaner energy markets (FT 9/11/2010)

A possible variety within this type of pattern is what Semino (2008: 105) terms situational triggering which occurs where the metaphorical motivation, rather than from the subject matter proper, springs specifically from the background situation or context of that subject matter. This is also found in Kovecses' (2009: 22) analysis of what he terms "context 
induced creativity”. In some cases, topic-triggering and situational triggering may overlap and merge. Headline writers take advantage of this type of source and obviously the lack of such source knowledge may be yet another stumbling block for the NNS. In the following cases, background knowledge is essential to capturing the full import of the headlines.

31) Dublin or quits (FT 15/11/2010)

32) Spellbound fans break records for Harry Potter (FT 21/1/2010)

33) Smoke gets in your eyes: How smoking affects your eye health (Irish Independent 21/11/2010)

The wager formula of Double or quits is substituted for the closely sounding Dublin and the reader must be aware of this juggling, plus the background knowledge of the financial crisis in Ireland, to understand and appreciate the artifice. In the second example, the background knowledge that magic and its likes are staple devices in Harry Potter makes the use of spellbound all the more effective. In the third instance, the background is the wellknown lyric which is tapped simply because the issue has to do with the detrimental effects of smoke on eye health.

A common denominator in all the examples of this section is the linguistic engineering that has gone into their composition. This deliberate strategy not only gets a meaning across but draws the reader's attention to the artifice mustered to do so more effectively. Therefore, as well as the semantic import, the reader is forced to notice the accompanying ingenuity, wit or humour and, ostensibly, this has an added effect for that reader in question. Since ingenuity, wit and humour are graded issues, subjective factors are involved here. Further strategies adding to the overall communicative effect, which I claim enhance these elements, can be pinpointed. These derive from how ingenious the linguistic manipulative strategy may be perceived to be by the reader. We have seen that all the foregoing examples in some way or other evidence a deliberate strategy whereby the choice of words in the headline raises reader awareness regarding the strategy employed, drawing his or her attention not only to the semantic content but to the linguistic forms expressing that content.

This awareness raising is more intrusive or more evident in particular cases and in these cases analysis can also reveal patterning. For instance, when fixed expressions are cleverly given some form of shift or other or where punning or wordplay are foregrounded, the sense of deliberate strategy or linguistic manipulation is all the more marked and this too, I claim, is a productive headline strategy.

34) Is a degree in homeopathy a sick joke? (FT 23/5/2009)

35) Italians cross over crucifix ban (Irish Times 2/11/2009) 
36) Pay and dismay (FT 12/8/2009) - referring to the apparently outrageous situation where banking executives were in receipt of enormous salaries and bonuses in the context of dismal bank performance during the crisis.

37) More Kraft required (FT 8/9/2009)

38) When we're out, we still can let you in (Irish Times 10/9/2009) - referring to remote control technology offered by modern information technology for house safety and control.

39) Revival of the fittest (FT 10/8/2010)

40) Merkel makes a mark (FT 5/6/2009)

As well as interface, all these examples additionally involve a high degree of play or wit. In 34), sick joke, meaning a joke in bad taste or causing disgust, is skilfully steered backwardly towards the literal meaning of sick because of the subject matter being a health issue. In 35), the meaning of cross as annoyed is cleverly punned with cross in the crucifixion sense. Example 36) taps the ubiquitous parking sign of current times pay and display. In 37) referring to the takeover of Cadbury by Kraft, the title of the latter company is effectively punned to suggest craft. Example 38) gives a very effective counter-positioning of out and let in. Number 39) adroitly cashes in on phonic proximity with Spencer's expression, given widespread currency by Darwin. In 40), as the context refers to finance and Merkel is the German Chancellor, the fixed expression makes a mark simultaneously refers back to the days of the German currency, (Deutch)mark.

\section{DISCUSSION}

The major questions are in what way and how all these strategies contribute to the discourse. What difference does it make to use these strategies rather than using more conventional word stringing? Does the greater processing cost deliver greater communicative benefit? Analysing the linguistic effects engendered by the strategies in question will throw light on these matters. Some are more obvious than others, but all are quite far reaching. Perhaps most immediately visible are the cohesion and coherence effects these devices set up. Ever since the classical works by Halliday and Hasan (1976) and Hoey (1991; 2005) linguists are conscious of the core role of these devices in underpinning discourse. They trigger networks of interrelation within texts and such networks are essential in text construction and, especially, they play a crucial role in aiding and abetting communication. From the examples of alliteration, here the link is the simple sound repetition, to the more complex interface examples, where the literal-figurative tension is heightened by the unexpectedness of a source-target shift, the devices enhance the sense of to-do-withness thereby facilitating how the text hangs together in the Hallidayan sense. 
By choosing alliteration, rhyme and rhythm, headline writers are tapping into the principle ingrained in language usage which is, as Boers and Linstromberg (2008: 330) put it regarding fixed expressions, "euphonious word strings are preferred over same-meaning but non-euphonious word strings". Following that pattern is thus by its very nature a communicative boon and consequently gives the headline that extra punch or energy characteristic of that discourse type. Thus, processing cost is rewarded by substantial communicative benefit.

What consequences might this practice have for the FLL? On the one hand, many a foreign language learner may completely overlook the linguistic engineering I have been highlighting in headlines and thus concomitantly lose out on the knock on effects: the communicative lure effected by that device, the satisfaction at recognising pattern, at recollecting fixed expression and the bonding that develops between producer and reader, all of which are so appealing for the native speaker. On the other hand, if headline word choice is driven by alliteration, rhyme or rhythm then the resulting word string may easily be a far less conventional combination and may all the more easily perplex the FLL.

In so far as the interface, double-grounding or topic-triggering pattern of headlines, the linguistic principles at work are considerably more complex. In the first place, it is useful to remember that the early corpus studies by John Sinclair were decisive in bringing home to the Anglo-Saxon world of linguistics the sheer prevalence of the phraseological in ordinary language usage ${ }^{5}$ :

The overwhelming nature of this evidence leads us to elevate the principle of idiom from being a rather minor feature, compared with grammar, to being at least as important as grammar in the explanation of how meaning arises in text. (Sinclair, 1991: 112).

How headlines exploit phraseology, by both using it and by countering expected patterns, is a major contributor to headline creativity. Phraseology provides language with ready-made chunks which are psychologically real (Partington, 2009; Gibbs \& Matlock, 2008) and which speakers can regularly call on as wholes. They are highly shared by a language community (Dobrovol'skij \& Piirainen, 2005: 31) which in forging them have hit upon a very apt manner of capturing a body of semantic content. Thus, partial components create expectations for the whole unit or for the semantic content of that unit. Consequently, to tamper with them is a major modification if not manipulation. Such modification or manipulation cannot but be highly creative since the fixedness of the received phraseological unit is a fortress militating against variation. Moreover, Brône and Coulson's (2010: 222ff) work provides experimental evidence for the psychological reality of the products of doublegrounding or interface as used in headlines. Additionally such phraseological variations, as we have pointed out elsewhere (Herrera Soler, 2006; Herrera \& White, 2007; Herrera \& White, 2010), create a complicity between speakers and hearers since both speaker or producer's ingenuity is matched by the hearer or reader in that the latter's capacity to 
recognise the ingenuity involved shows he or she is up to the challenge posed by the former. To spell out how the overall process operates, let us consider the following examples:

41) Hotels’ silver lining could have a cloud (Irish Times 29/8/2010)

The fixed expression every cloud has a silver lining, meaning a positive aspect can always be found in something which is negative overall, is here turned around to the meaning that something that is positive overall may entail a negative element. In the above instance, the meaning is that the anticipated recovery of strong demand for late summer holidays (the positive aspect or silver lining in a negative context) might not live up to expectations (the negative aspect or cloud in a positive context). The claim I am making here is that the particular linguistic form (a complete turn around of a fixed idiomatic expression) not only gets across the particular semantic content just outlined, but it does so with great communicative impact because it gets that content across via a linguistic form that runs counter to established form and hence counter to expectation. The same point is illustrated by the following example:

42) In gold they rush (FT 13/11/2010)

This headline dealing with the spectacular spike in gold prices at the present time (2010) appears with the pictorial accompaniment of a US gold coin ${ }^{6}$. The motto In God we trust, appearing on US currency is without doubt an utterly entrenched expression to be taken as a whole. Both the syntactic form (the powerful fronting of in God) and the semantic content of elevated moral sentiment make the expression all the more inexpugnable. However, the headline writer has managed to subvert this with the pivotal substitutions of gold and rush which both subvert the original and additionally link up with another fixed expression gold rush. The communicative impact deriving from these factors is a fitting mechanism to get across the message of a veritable paradigm change in the valuation of gold at this juncture of global crisis.

A corollary of the strategies deployed in headline word choice is that they are inextricably tied up with wit and humour. The mere juxtapositions and counter saliency meanings brought about evidence an ingenious play on words. Paradoxically as it may seem, playing with language is a very serious business. This is because as Yaguello (1995: 3) states:

Playing after all presupposes that one knows the rules and how to bend them, how to exploit the ambiguity which characterizes natural languages, as well as the creativity which they allow... all wordplay presupposes correct acquisition of the code.

Therefore play provides a greater insight into the workings of that system, highlights the polysemy and ambiguity available in language and taps its potential. Moreover, the type of 
play here involved, where the artifice and the expected form are easily recoverable, complies with Giora et al's (2004) notion of pleasurability optimisation. Brône and Coulson (2010: 225ff) have further substantiated the role of playfulness, providing experimental evidence supporting the wittiness claim for double-grounding headlines. Additionally, they highlight features specific to double-grounding which distinguishes it from the saliency examples contemplated in Giora et al. (2004). Their experiments showed that: "Double-grounded metaphors took longer to read and were consistently rated as wittier than single-grounded ones” (Brône \& Coulson, 2010: 230). On a relevance cost benefit bases, therefore, double grounding implies greater cost but that cost is rewarded with qualitative benefit increase by way of communication potential. Furthermore, Partington's (2009: 1779) statement as to the effect of the manipulation of normal priming prosody can be extended to cover all the above strategies, namely, "[t]he effect achieved is a general revitalisation of the language at that point of the text. Novelty breathes life into the discourse."

In claiming a plus in communicative potential for the type of headline we have been highlighting, in addition to all the above considerations, we may add evidence deriving from the phenomenon known as memory hooks. This device, extensively used in slogans, mottos and advertisements for business networking, and hence aimed at catching and retaining reader attention, characteristically exploits interface or double grounding with the added wit or humour factor prevalent ${ }^{7}$. If the function of memory hooks is to be communicative, if the device is held to be highly effective in this respect and if they characteristically exploit interface or double grounding, then it follows that this pattern is a manifestly communicative bonus.

As encouragement to the Spanish speaking ESP student, some headlines in their own language, exploiting the strategies highlighted in the English evidence, may be provided to bring home to the Spanish student the complexity of the workings of the device. Dwelling on the strategy being exploited in the student's own mother tongue or, for instance, having to explain such headlines to NNS's of Spanish (Erasmus students, for example,) could raise awareness towards the strategies underlying headlines and increase the trade off from tackling the corresponding headlines in English. Equally, translations of English headlines to Spanish and Spanish headlines to English could also help to familiarise students with the strategies involved (Samaniego Fernández, 2007; 2010). For instance, the following series of Spanish headline examples all evidence what Kovecses (2009: 22) termed context induced creativity both of the topic and situational type of triggering (Semino, 2008: 105) - and the exercise of explaining them would involve ferreting out information about the respective contexts of each case:

43) Borrachera de Guinness? (El Economista -paper edition- 24/11/2010) 
Here the context is the Irish financial crisis and its consequences. To understand this headline, it is essential to provide considerable situational information: e.g., Guinness being a characteristic drink in Ireland can metonymically activate that country while over indulgence in that alcoholic drink may lead to dire consequences that require a recovery period and this source operates metaphorically to capture the excesses of bank lending in Ireland leading to the property bubble and the catastrophic consequences this triggered.

44) El volcán reducirá a cenizas los beneficios de las aerolíneas (El Economista $19 / 4 / 2010)$

Topic and situational information are involved here: the nature of volcanoes to erupt launching ashes into the atmosphere and the situation arising for air transport in the context of the Icelandic eruption. At the same time, the headline exploits interface or double grounding, adeptly raising the play between the literal volcanic ash and the fixed expression -reducir $a$ cenizas- meaning utterly destroy, thereby endowing the headline with added communicative force.

45) El negocio del toro se desangra en la ganadería (El Mundo 3/1/2009)

This headline exploits the interface strategy, playing on the literal reference to bravebull bleeding and its figurative meaning as detrimental to Bullfighting as an economic concern.

46) Slavica deja a Ecclestone en el chasis (El Economista)

The situational knowledge that Ecclestone is an F1 magnate, that Slavica was his exwife and that divorce settlements in the cases of wealthy personages seriously hit personal fortunes are all relevant to understanding this headline. The communicative impact is particularly influenced by exploiting the topic -the racing-car world- for its interface value: the technical vocabulary term -chasis- adroitly used metaphorically to capture the severe pecuniary losses of the magnate.

47) Dani Martín no se chupa el dedo (El Mundo -paper edition- 21/11/2010)

This headline impacts because of the communicative potential of the fixed expression chuparse el dedo- likely to be shared by native Spanish speakers. However, that impact would be all the more marked and all the more coherent when seen in the light of the situational information, namely, that the headline introduces a report of a concert given by Dani Martin where the chief sponsor was the ChupaChups company. This knowledge enables 
the reader to understand and enjoy the linguistic ingenuity and wit of the situational connection between the company name and the fixed expression.

The following examples pursue the same strategy to maximize communicative potentiality:

48) La hostelería echa humo (El Mundo -paper edition- 16/11/2010)

In the context of the pending smoking-ban legislation in bars and cafés, this headline exploits interface or double grounding by linking the metaphoric fixed expression -echar humo- with smoke in its literal sense.

49) General Motors vuelve a rugir en bolsa (El Economista 18/11/2010)

Here the interface connection between engine sound and economic performance is exploited.

\section{CONCLUSION}

This article has examined the prosodic, syntactic and semantic patterns used in crafting headlines for the purpose of grabbing reader attention and which, it is claimed, may potentially give rise to added difficulty for the ESP student. The result is a discourse which is highly luring for the NS but this communicative asset may not only be lost on the NNS but may even become a major impediment to understanding. By outlining the linguistic strategies deployed by headline writers, we may avert this potential difficulty and empower the ESP student to gain a better insight into the idiomaticity of English. This claim is made on the grounds that playing with or manipulating language is a sign of prior mastery of the code and hence a close examination of such a procedure provides the student with a privileged window onto how that code works, thus allowing him or her to gain a better understanding of the language itself (Yaguello, 1995). I first pinpointed phonic (the use of alliteration and rhyme) and syntactic patters (phrase structure and use of ENPs) showing how these condition word choice and phrase structuring. A parsing approach to the latter complex structures was aimed not only at providing students with an explanation but with supplying them with tools to handle such structures and hence crack the headline code. Numerous advantages spring from this procedure. It should wane students from the vice of single word focus and encourage them to pay attention to the phrase. In other words, it would guide them towards a more phraseological approach.

On the other hand, the complexity involved in these headlines was also seen as a consequence of the headline struggle to pack the greatest amount of meaning into the smallest 
space possible. As a result, rather than seeing standard headline criteria (for example, those outlined by Dor (2003) as hard and fast requirements, these criteria should be seen to cohabitate, compete and even enter into conflict. For instance, the clarity criteria could be overridden by ambiguity in cases where the latter could provide additional communicative import. Headline word choice was shown to be conditioned not alone by meaning but by phonic, syntactic, thematic and situational imperatives. I also analysed the strategy of fixed expression and idiomatic usage and the deliberate modification of these items as a means of cashing in on ready made communicative meaning chunks, on the one hand, and, on the other, triggering extra communicative potential by creatively varying what are thought of as invariable forms (Herrera \& White, 2010). Finally, the phenomenon of interface, double grounding or topic triggered metaphor is amply dealt with as a characteristic feature of headline discourse showing it to be a highly communicative asset: it fosters cohesion and coherence, it adds an element of wit and it creatively exploits metaphor. The final conclusion is that familiarity with these strategies could be immensely rewarding to the ESP student enabling him or her to crack the apparently arcane headline code and thereby qualitatively advance in idiomaticity skills. As a pedagogic aid to this end, some Spanish headlines evidencing similar devices were contemplated.

\section{NOTES}

${ }^{1}$ Bell (1991: 189) states: Headlines are not just a summary but part of news rhetoric whose function is to attract the reader. According to Dor (2003: 708ff), headlines are to be short, clear, easy to understand and unambiguous, among others.

${ }^{2}$ In previous research, we had been calling this pattern interrelation (see White, Herrera \& Amengual, 2004; Herrera Soler, H., M. White, B. Villacañas \& M. Amengual, 2006).

${ }^{3}$ Creative crafting for communicative effect is equally found in research article titles, e.g., "Biotech as biothreat?" (Holmgreen, 2008).

${ }^{4}$ Instantiations come from on-line editions unless otherwise specified, emphasis added by author.

${ }^{5}$ Though a strong tradition in research in this direction in the non-English speaking linguistic world already existed: "In contrast to the prosperous phraseological research in Eastern and Western Europe since the 1970s, ..., there is no comparable tradition in Anglo-Saxon linguistics. This gap in English language research (lexicology and lexicography) has been recognised several times.” (Dobrovol'skij \& Piirainen, 2005: 31).

${ }^{6}$ For insightful recent work on how text and picture combine, see Martín de la Rosa (2009) and Cortés del los Rios (2010).

${ }^{7}$ See http://www.memoryhooks.com/hooks.htm for an extensive list. A few sample examples are; Accounting: 'The company you can account on', 'we make life less taxing', 'your bottom line is my top priority'. Auto repair: 'We don’t just meet by accident'. Flooring: 'We will floor you with our service'. Accessed 20/11/2010. 


\section{REFERENCES}

Baicchi, A. (2003). Relational complexity of titles and texts: A semiotic taxonomy. In L. Merlini Barbaresi (Ed.), Complexity in Language and Text (pp. 319-341). Pisa: Edizione PlusUniversidad de Pisa.

Bell, A. (1991). The Language of News Media. Oxford: Blackwell.

Boers F., \& Lindstromberg, S. (2008). Structural elaboration by the sound (and feel) of it. In: Boers, F. and Lindstromberg S. (Eds.), Cognitive Linguistic Approaches to Teaching Vocabulary and Phraseology (pp. 329-353). Berlin and New York: Mouton de Gruyter.

Brône, G. \& F. Feyaerts (2005). Headlines and cartoons in the economic press: Double grounding as a discourse supportive strategy. In G. Erreygers and G. Jacobs (Eds.), Language, Communication and the Economy (pp. 73-99). Amsterdam: John Benjamins.

Brône, G. \& Coulson, S. (2010). Processing deliberate ambiguity in newspaper headlines: Double grounding. Discourse Processes, 47(3), 212-236.

Cortés de los Ríos, M.E. (2010). Cognitive devices to communicate the economic crisis: An analysis through covers in The Economist. Ibérica, 20, 81-106.

Crawford Camiciottoli, B. (2007). The Language of Business Studies Lectures. Amsterdam: John Benjamins.

Durán, P., \& Roldán, A. (2008). The role of context in the interpretation of academic and professional communication. In Gibert Maceda, T. and Alba Juez, L (Eds.). Estudios de Filología Inglesa. Homenaje a la Dra. Asunción Alba (pp.81-95). Madrid: UNED.

Dobrovol'skij, D. \& Piirainen, E. (2005). Figurative Language: Cross-Cultural and Cross-Linguistics Perspectives. Current Research in Semantic/Pragmatics Interface: Vol. 13. Amsterdam: Elsevier.

Dor, D. (2003). On Newspaper Headlines as Relevance Optimisers. Journal of Pragmatics, 35, 695721.

Galtung J, \& Ruge, M.H., (1965). The Structure of Foreign News. Journal of Peace Research, 2(1), 64-91.

Gibbs, R. W. \& Matlock, T. (2008). Metaphor, imagination, and simulation. Psycholinguistic evidence. In Gibbs, R. W. (Ed.), The Cambridge Handbook of Metaphor and Thought (161176). Cambridge: Cambridge University Press.

Giora, R. (2003). On Our Mind. Salience, Context and Figurative Language. Oxford: Oxford University Press.

Giora, R. (2008). Is metaphor unique? In Gibbs, R. W. (Ed.), The Cambridge Handbook of Metaphor and Thought (pp.142-160). Cambridge: Cambridge University Press.

Giora, R., O. Fein, A. Kronrod, I. Elnatan, N. Shuval and Adi Zur (2004). 'Weapons of Mass Distraction: Optimal Innovation and Pleasure Ratings', Metaphor and Symbol, 19 (2), 115-141.

Halliday, M.A.K. \& Hasan, R. (1976) Cohesion in English. London and New York: Longman.

Herrera Soler, H. (2006). Conceptual Metaphors in Press Headlines on Globalisation. Annual Review of Cognitive Linguistics, 4, 1-20.

Herrera Soler, H., White, M., Villacañas, B. \& Amengual, M. (2006). Figurative Language in English and Spanish Business Press Headlines and its Effects on Inter- and Intra-Cultural Communication. Universidad de Essen. LAUD Paper $N^{\circ} 661$, pp. 1-27.

Herrera Soler, H. and M. White. (2007). A contrastive view of British and Spanish business press headlines. Rassegna Italiana di Linguistica Applicata (RILA), Anno XXXIX, Gennaio-Agosto/12, 295-316.

Herrera, H. and White, M. (2010). Canonicity and variation in idiomatic expressions: Evidence from business press headlines. In: Knop, S. de, Boers, F., and Rycker, A.de, Fostering Language Teaching Efficiency Through Cognitive Linguistics (pp. 167-187). Berlin and New York: Mouton de Gruyter.

Hoey, M. (1991). Patterns of Lexis in Text. Oxford: Oxford University Press.

Hoey, M. (2005). Lexical Priming. A New Theory of Words and Language. London: Routledge.

Holmgreen, L-L. (2008). Biotech as 'Biothreat'?: Metaphorical Constructions in Discourse. Discourse and Society, 19(1), 99-119 
Ifantidou, E. (2009). Newspaper Headlines and Relevance: Ad Hoc Concepts in Ad Hoc Contexts. Journal of Pragmatics, 41, 699-720.

Koller, V. (2004). Businesswomen and war metaphors: possessive, jealous and 'pugnacious?' Journal of Sociolinguists, 8 (1), 3-22.

Kovecses, Z. (2009). The Effect of Context on the Use of Metaphor in Discourse. Ibérica, 17, 11-23.

Lakoff, G. \& Turner, M. (1989). More than Cool Reason. A Field Guide to Poetic Metaphor. Chicago: The University of Chicago Press.

Langlotz, A. (2007). Idiomatic Creativity. Amsterdam: John Benjamins.

Martín de la Rosa, V. (2009). The Role of Pictorial Metaphor in Magazine Advertising. Revista Alicantina de Estudios Ingleses, 22, 167-180.

Partington, A. Scott (2009). A Linguistic Account of Wordplay: The Lexical Grammar of Punning. Journal of Pragmatics, 41, 1794-1809.

Samaniego Fernández, E. (2007). El impacto de la lingüística cognitiva en los estudios de traducción. In Pedro Fuertes Olivera (Coord.), Problemas Lingüísticos de la Traducción Especializada (pp. 119-154). Universidad de Valladolid: Secretariado de Publicaciones.

Samaniego Fernández, E. (2011). Translation Studies and the Cognitive Theory of Metaphor. Review of Cognitive Linguistics. 9(1), 262-279.

Semino, E. (2008). Metaphor in Discourse. Cambridge: Cambridge University Press.

Sinclair, J. (1991). Corpus, Concordance, Collocation. Oxford: Oxford University Press.

White, M. (2006). Language synergies and communication felicity. In M. Carretero, L.Hidalgo, J. Lavid, E. Martínez, J. Neff, S. Pérez de Ayala and E. Sánchez-Pardo (Eds.), A Peasure of Life in Words. A Festschrift for Angela Downing. (vol. I: pp. 561-588). Madrid: Universidad Complutense.

White, M. \& Herrera, H. (2009). How business press headlines get their message across: a different perspective on metaphor. In A. Musolff and Zinken, J (Eds.), Metaphor and Discourse (pp.135152). Basingstoke: Palgrave-Macmillan.

White, M., Herrera, H. \& Amengual, M. (2004). Interrelation between content and expression in news headlines. In S. Sainz, I. y Ángel F. Lago (Eds.), Current Trends of Languages for Specific Purposes in an International and Multicultural Context (pp. 239-249). Granada: Universidad de Granada.

Yaguello, M. (1998). Language Through the Looking Glass. Oxford: Oxford University Press. 